\title{
OS EFEITOS NEGATIVOS DA CORRUPÇÃO NAS INSTITUIÇÕES PÚBLICAS E NO REGIME DEMOCRÁTICO
}

\author{
THE NEGATIVE EFFECTS OF CORRUPTION IN PUBLIC INSTITUTIONS
}

\section{AND IN THE DEMOCRATIC REGIME}

\begin{abstract}
Caroline Fockink É pós doutoranda em Direito, realizando sua pesquisa de pós-doutoramento em Direitos Fundamentais, na PUC de Porto Alegre/RS. É doutora em Direito na Universidade de Santa Cruz do Sul - UNISC. É mestre em Direito, ambos pela Universidade de Santa Cruz do Sul (2007). É especialista em Direito Penal e Processual Penal e possui graduação em Direito pela Universidade de Santa Cruz do Sul (2000).
\end{abstract}

\section{Resumo}

O presente artigo científico busca responder ao problema: quais as consequências da corrupção nas instituições públicas e no regime democrático? Para se alcançar a resposta, este estudo propõe três objetivos específicos, abordados respectivamente em três partes. $\mathrm{O}$ primeiro é demonstrar a importância de as pessoas confiarem nas instituições públicas, que devem espelhar o primado da lei, compreendido como sendo o propósito de sua criação para atender as necessidades públicas, demandas sociais, agindo com probidade. $\mathrm{Na}$ segunda parte, o objetivo é analisar a ocorrência da corrupção na esfera pública e as consequências que esta causa justamente na confiança que a sociedade deve ter nas instituições públicas. Finalmente, no terceiro propósito, é destacar os efeitos que a corrupção pública produz na qualidade do regime democrático, impactando negativamente na legitimidade deste. A democracia exige altos níveis de confiança pública nos mecanismos institucionais e, quando a corrupção deteriora a confiança que a sociedade deveria ter nas instituições, afeta, como consequência, a qualidade do regime democrático e o apoio que os indivíduos devem dar a ele. A corrupção diminui a adesão ao regime provocando apatia social. Estimula a aceitação de escolhas autoritárias amplamente divulgadas pela extrema direita, que conta com apoio popular, defendidas como boas alternativas contra o regime em situações de crise. O método de abordagem adotado no desenvolvimento deste trabalho é o dedutivo. O método de procedimento é o histórico-crítico e em termos de técnica da pesquisa, utilizou-se documentação indireta, com consulta em bibliografia de fontes primárias e secundárias. 
Palavras chave: corrupção. Confiança. Instituições públicas. Regime democrático.

\begin{abstract}
This scientific paper aims to answer the problem: what are the consequences of corruption in public institutions and in the democratic regime? In order to achieve the response, this study proposes three specific objectives, addressed in its three parts, respectively. The first objective is to demonstrate the importance of people trust in public institutions, which should reflect the rule of law, understood as being their creation purpose to meet public needs, social demands, acting with probity. In the second part, the aim is to analyze the occurrence of corruption in public sphere and the consequences caused by it exactly in the confidence society must have in public institutions. Finally, in the third section, the goal is to show the public corruption effects on the democratic regime quality, negatively impacting on its legitimacy. Democracy requires high levels of public confidence in institutional mechanisms, and when corruption undermines the confidence society should have in institutions, it affects, as a consequence, the quality of democratic regime and the support individuals must have in it. The corruption also reduces the scheme joining, leading to social apathy. It encourages authoritarian choices acceptance broadly available by the extreme-right, which have popular support and are advocated as sound alternatives against the regime in crisis situations. The approach method adopted in this article development is the deductive. The procedure method is the historical-critical and, in terms of researching technique, it was used indirect documentation, with bibliographical references from both primary and secondary sources.
\end{abstract}

Keywords: corruption. Confidence. Public Institutions. Democratic regime.

\title{
CONSIDERAÇÕES INICIAIS
}

O presente artigo científico se propõe a responder a seguinte pergunta, que é o seu problema central: quais as consequências da corrupção nas instituições públicas e no regime democrático? Para se alcançar a resposta, este estudo divide-se em três pontos específicos, com um objetivo próprio que será buscado em cada uma dessas três partes.

O primeiro objetivo é demonstrar a importância de as pessoas confiarem nas instituições públicas, que devem espelhar o chamado "primado da lei", que é justamente o propósito de sua criação, para ir ao encontro das necessidades públicas, agir com probidade, visando sempre a satisfazer demandas sociais, para as quais foram criadas. Posteriormente, ter-se-á como objetivo analisar a ocorrência da corrupção na esfera pública e as consequências que esta causa na confiança que a sociedade deve ter nas instituições públicas. Demonstrar que a corrupção quebra a necessária corrente de 
confiança, gerando desconfiança e descrédito nas instituições públicas, pois quando existem práticas corruptivas as instituições se desviam da sua proposta de existência, que é a de atender o interesse público. Finalmente, busca-se demonstrar os efeitos que a corrupção pública traz na qualidade do regime democrático, fomentando ideias extremistas, exaltadas por movimentos de extrema direita, discurso do ódio, que resgatam ideias racistas e preconceitos há muito superados e provoca a apatia social em participar da vida política e democrática da sociedade.

Para responder o problema da pesquisa e alcançar os três objetivos específicos propostos, o presente artigo científico divide-se em três partes: Na primeira se quer abordar e conceituar as instituições públicas, ressaltando a importância de a sociedade confiar nelas. A segunda parte, examina a corrupção na esfera pública e as consequências negativas que ela causa com relação à confiança que a sociedade deve ter nas instituições públicas. Finalmente, na terceira e última parte, analisa-se, algumas das principais consequências e efeitos negativos da corrupção pública na qualidade do regime democrático, demonstrando que, justamente o enfraquecimento da democracia dá ensejo para discursos extremistas, que pregam a volta de regimes ditatoriais, historicamente apoiados pela população e que ensejam o discurso do ódio, baseados em ideias racistas. Além disso, como última consequência negativa da corrupção, há ainda a apatia social das pessoas em participar na vida democrática e política da sociedade.

$\mathrm{O}$ método de abordagem adotado no desenvolvimento deste trabalho foi $\mathrm{O}$ dedutivo. Já como método de procedimento, trabalhou-se com o histórico-crítico que, procura situar no tempo a matéria objeto do estudo. Em termos de técnica da pesquisa, utilizou-se documentação indireta, com consulta em bibliografia de fontes primárias e secundárias.

\section{INSTITUIÇÕES PÚBLICAS E A IMPORTÂNCIA DE A SOCIEDADE CONFIAR NELAS}

Para falar da realidade das práticas corruptivas nas instituições e as consequências negativas, como, principalmente, a de causar a desconfiança das pessoas nas instituições, é necessário observar que a chamada "institucionalidade corruptiva" também apresenta elementos históricos.

Abordando, para fins de exemplificação, a sociedade colonial brasileira, Leal (2013, p, 138-143) destaca como sendo uma das suas principais características, a 
incoerência e a instabilidade no povoamento, a pobreza e a miséria na economia, a dissolução nos costumes, a inércia e a corrupção dos dirigentes leigos e eclesiásticos. Desde o tempo colonial, ocorreu uma reprodução na matriz política da Coroa Portuguesa, referente à gestão e às políticas aplicadas no Brasil-colônia. Ou seja, desde o início, a corrupção faz parte da história nacional. A desorganização do governo e do Estado português foi transferida à colônia brasileira, com muitas particularidades, como, por exemplo: leis confusas, morosidade e ineficiência das estruturas administrativas. Não havia sistema jurídico operoso e ocorria uma enorme confusão entre o público e o privado, ou seja, houve a possessão do espaço público pelo privado e, também, por agentes públicos corruptos. Eram altos índices de práticas e aceitação de práticas corruptivas.

As instituições públicas são consideradas mecanismos de mediação política, constituídos conforme as escolhas que a sociedade faz. Possuem o objetivo de satisfazer às expectativas públicas, atendendo os interesses sociais para os quais foram criadas. A ocorrência da corrupção, nas instituições brasileiras, compromete a eficiência de gestão e, consequentemente, sua credibilidade, ou seja, a confiança que a população nelas deveria.

A confiança nas instituições públicas assume especial importância para que elas efetivamente funcionem, levem em conta os interesses sociais a que foram criadas e tenham reflexos positivos com relação à democracia. Para justificar essa afirmação, fazse necessário apontar algumas definições do que vem a ser esta confiança e também a sua importância com relação às instituições públicas.

A confiança nas instituições é considerada um elemento fundamental, pois elas são criadas legalmente para atender às demandas sociais, prestando segurança pública, assistência jurisdicional e demais serviços sociais necessários e estabelecidos legalmente. O objetivo na criação de uma instituição pública justamente está centrado no dever de dar atenção, com eficiência, honestidade e probidade ao propósito a que foi criada. Quando isso ocorre, cria-se um círculo positivo de confiança da população nas instituições. A instituição pública está, então, respondendo positivamente às expectativas sociais.

Argumenta Cunha (2014, p. 70), que todas as sociedades estão unidas por laços de confiança, sendo, umas mais que outras. A confiança social, para ele, é essencial para que os indivíduos e as comunidades sejam consideradas saudáveis e funcionais. Ressalta que o conceito de confiança é multifacetado, podendo estar ligado a 
percepções relativas à competência, benevolência e honestidade. Essas relevantes percepções, com relação à generalidade das pessoas, não são compatíveis quando a realidade demostra que existem altos graus de corrupção nas instituições.

$\mathrm{Na}$ bibliografia estrangeira, buscou-se como fonte as palavras de Rothstein (2005, p. 41) que analisa os aspectos positivos de existir confiança. Partindo de sua análise a um nível individual, observa-se que as pessoas ao acreditarem que outras, na sua sociedade, podem ser confiáveis, estão mais inclinadas a ter uma visão positiva de suas instituições democráticas. Da mesma forma, essas pessoas terão mais propensão a participar da política e a serem mais ativas nas organizações cívicas. Elas também serão mais caridosas e tolerantes com as minorias.

Quando existe confiança, as pessoas tendem ainda a ser mais otimistas com relação a sua própria capacidade de influenciar suas chances de vida e serão, também, mais felizes com o modo como vivem. Explica, que as cidades, as regiões e os países, com indivíduos mais confiantes, tendem a ter melhores instituições democráticas de trabalho, economias mais abertas, maior crescimento econômico e menos crime e corrupção. ${ }^{1}$

Moisés (2013b, p. 39-49) por sua vez, diz que confiança, em linguagem comum, quer dizer segurança de procedimento ou crença em outros com quem se interage e se convive. Para ele, confiar nas instituições pressupõe conhecer, de alguma forma, a ideia básica ou a função específica que foi atribuída a ela, como, por exemplo, acreditar que a política existe para garantir a segurança e a sobrevivência das pessoas. Confiança em instituições é uma forma pela qual os cidadãos asseguram que os seus direitos de cidadania são respeitados. Ao mesmo tempo, representam a maneira pela qual confirmam o seu compromisso com as exigências de seu pertencimento à comunidade política. Para o referido autor, a cuja opinião este estudo se filia, confiança é, assim, uma condição necessária para a cidadania, e o seu meio de realização são precisamente as instituições democráticas.

\footnotetext{
${ }^{1}$ At the individual level, people who believe that in general most of other people in their society can be trusted are also more inclined to have a positive view of their democratic institutions, to participate more in politics, and to be more active in civic organizations. They also give more to charity and are more tolerant toward minorities and to people who are not like themselves. Trusting people also tend to be more optimistic about their own ability to influence their own life chances and, not least important, to be more happy with how their life is going. [...] Cities, regions, and countries with more trusting people are likely to have better working democratic institutions, to have more open economies, greater economic growth, and less crime and corruption.
} 
A confiança política dos cidadãos nas instituições depende da coerência das mesmas com os motivos e objetivos para que foram criados por lei. Ou seja, os motivos que justificam a sua existência, como também o funcionamento da instituição, é que ajudam a determinar a medida dessa confiança, que pode ou não se estender aos responsáveis por elas. Isso depende de quanto o comportamento da instituição é compatível com objetivos que foram determinados legalmente para ela.

Essa dinâmica, a experiência dos cidadãos com as instituições, no sentido de atenderem efetivamente os fins para que foram criadas legalmente, determina a ocorrência da confiança nelas. A confiança política dos cidadãos para com as instituições não é automática, vai depender sempre de as instituições estarem organizadas para permitirem que os cidadãos conheçam, recorram a elas buscando o que foi determinado legalmente para ser por elas atendido.

Seguindo esta ideia, arremata Cunha (2014, p. 69-70) que a confiança social é considerada como sendo um dos bens mais valiosos de qualquer comunidade política. Exemplifica no sentido de que: quando se trata da confiança social de um indivíduo, está-se falando a respeito do quanto ele acredita que terá respeitados os seus direitos e que as instituições irão cumprir sua palavra.

O que é consenso é que a confiança nas instituições depende de elas estarem atendendo, com probidade, eficiência e honestidade o objetivo para a qual foram legalmente criadas. Através delas é que o Estado presta à população seus principais serviços. As instituições públicas, além de executarem seus fins de forma proba e eficiente, devem atender também os fins éticos a que foram propostos.

Baseando-se mais uma vez, em bibliografia estrangeira, nas palavras de Cortina (1998, p. 98), as instituições e organizações públicas devem executar suas atividades eticamente, para, assim, possuírem legitimidade, diante de uma cidadania cada vez mais consciente. E essa viabilidade em realizar a sua missão, é a obrigação ligada a qualquer organização. $^{2}$

Assim, pergunta-se por que é tão importante confiar nas instituições? Conforme a teoria democrática, a importância da confiança nas instituições está exatamente no

\footnotetext{
${ }^{2}$ Sin embargo, no es menos cierto que también la ética tiene un valor de uso, y no sólo la ética personal, sino también la ética de las organizaciones e instituciones de la vida pública, que es la que ahora nos importa. También es cierto que las instituciones y organizaciones públicas sólo si funcionam eticamente ganan la legitimidad a que deben hacerse acreedoras ante una ciudadanía cada vez más consciente de serlo y también la viabilidad, el permanecer realizando su tarea, que es la obligación a la que está ligada cualquier organización.
} 
fato de que as democracias modernas deram para as instituições públicas o papel de mediadores dos interesses dos indivíduos.

As regras institucionais democráticas como a imparcialidade em eleições, a probidade no uso dos recursos públicos ou a igualdade de acesso à justiça, além de garantirem os direitos da cidadania, geram expectativas sociais positivas que dizem respeito ao funcionamento das instituições. Seguindo este raciocínio, e, em conformidade com as palavras de Moisés (2013b, p. 49), pode-se dizer que a confiança é uma condição necessária para a cidadania, e se concretiza precisamente nas instituições democráticas.

São as instituições que atuam na intermediação das relações entre os cidadãos e o sistema político. Conforme Meneguello (2013, p. 361), justamente esse seria o ponto que difere a democracia das demais formas de governo. Como são elas que agem na intermediação entre cidadãos e o sistema político, a confiança que se tem nas instituições reflete a percepção que a sociedade tem sobre o funcionamento do sistema como um todo. Consequentemente, ela seria definitiva com relação aos níveis de apoio e satisfação com o regime democrático.

Ademais, a confiança nas instituições está ligada diretamente à boa democracia, e pode ser relacionada à palavra estrangeira responsiveness, trazida por Mignozzetti (2013, p. 264), que significa responsividade, em tradução livre. Esta palavra pode ser definida no sentido de estar ocorrendo uma boa resposta, por parte dos governos e das instituições em atender às demandas e às necessidades dos cidadãos. Ou seja, a responsividade em uma boa democracia significa que os governos, como também as instituições, estão cumprindo, de forma efetiva, as expectativas que os indivíduos têm sobre elas, que as demandas sociais estão sendo plenamente atendidas.

\section{A CORRUPÇÃo QUE OCORRE NA ESFERA PÚBLICA E SUAS CONSEQUÊNCIAS NEGATIVAS COM RELAÇÃO À CONFIANÇA NAS INSTITUIÇÕES PÚBLICAS}

Montesquieu (2002, p. 125-145) ensinou que corrupção dos governantes quase sempre começa com a corrupção dos seus princípios. Quando os homens se desviam do dever de disporem sua própria vida ao serviço público, quando se convertem em vítimas da acumulação e se apropriam do bem comum para si mesmos, quando adotam uma atitude negligente ante a participação política e desviam o olhar para os assuntos de interesse privado, quando arriscam a segurança de todos em benefício próprio ou de 
poucos, ou seja, quando a virtude cívica fraqueja, se criam as condições para que apareça e se desenvolva a corrupção.

Atualmente, um dos problemas mais graves enfrentados pela coletividade é justamente garantir uma administração que seja proba. Diariamente, a população brasileira testemunha a publicização de vários escândalos de corrupção que envolvem agentes públicos e políticos de diversos escalões. Eles agem fazendo com que o Estado funcione a seu favor, ocorrendo uma total inversão de valores.

Apoiando-se, mais uma vez, nas palavras de Cortina (1998, p. 98-99), a corrupção ocorre há muitos anos, mas os escândalos publicizados nos anos setenta e oitenta, que aconteceram em países democráticos, lançaram a reflexão nessas sociedades sobre as consequências perversas da corrupção generalizada e tolerada, admitida por parte da sociedade. ${ }^{3}$

Conforme Lopes (2013, p. 311), foi a partir da década de 80 , que os estudos realizados em diversas partes do mundo vêm documentando o crescimento da desconfiança dos cidadãos com relação às instituições públicas. Essa desconfiança é entendida como uma síndrome de atitudes que envolvem principalmente o descrédito quanto ao funcionamento das instituições políticas, destacando-se aqui, justamente, as instituições de representação. A desconfiança ocorre tanto nas antigas quanto nas novas democracias, embora haja variações significativas entre os países e entre instituições no interior dos países.

Conforme Miranda (2014, http://www.conamp.org.br), esses escândalos de corrupção pública aumentam ainda mais o abismo social, prejudicando direitos essenciais da população. Deixam com isso o Brasil numa triste posição no cenário mundial: ser um país com um dos mais altos índices de desigualdade social, com diversas regiões entre as de menores índices de desenvolvimento humano do planeta.

Onde ocorre a corrupção pública? Livianu (2014, p.145) ajuda a responder esta pergunta, afirmando que ela atinge de forma mais direta e grave as instituições públicas, efetivando-se na política e na administração pública. Na política, é praticada com improbidade pelos governantes, que colocam a esfera pública a serviço do particular em detrimento do interesse geral, como deveriam atender. Com relação à corrupção que

\footnotetext{
${ }^{3}$ También la corrupción es entrada en años, pero los escândalos de los setenta y ochenta, conocidos y difundidos en países democráticos precisamente por la posibilidad de hacerlo, han puesto en marcha la reflexión en esas sociedades sobre las perversas consecuencias de la corrupción generalizada, y admitida en parte por la sociedad.
} 
ocorre no âmbito da administração, ela acontece quando os agentes públicos praticam atos contra os interesses da administração pública.

Com relação à corrupção pública, Bobbio, Matteucci e Pasquino (2000, p. 291292), trazem uma completa definição em seu Dicionário de Política. Argumentam que podem ser distinguidos três tipos de corrupção pública. O primeiro seria a prática do uso da recompensa escondida para mudar a seu favor o sentir de um funcionário público. $O$ segundo seria o nepotismo, ou concessão de empregos ou contratos públicos baseados não no mérito, mas nas relações de parentesco. E, o terceiro seria o peculato por desvio ou apropriação e destinação de fundos públicos ao uso privado. Com relação ao nepotismo, embora ele tenha uma certa aceitação por parte de determinada parcela da sociedade, configura um ato de corrupção extremamente danoso para a coletividade, pois, além de atentar contra o princípio da impessoalidade, deixando de lado a obrigatoriedade do concurso público, compromete seriamente a eficiência da Administração Pública.

Quando o funcionário público (lato sensu) adota comportamentos ilegais, buscando o seu enriquecimento ilícito, como também a satisfação pessoal ou de outrem, ou quando ele abusa do exercício da sua função, quem ficará em descrédito diante dos cidadãos, será o próprio ente público. Os cidadãos passam a ver o funcionário público como corrupto, que é mero instrumento colocado a serviço dos detentores do poder político e econômico e de seus apaniguados. Esta percepção, destacada por Prado (2004, p. 441-442), provoca efeitos nefastos, como o desrespeito dos cidadãos para com a lei e os bens públicos, a má-formação de novos agentes públicos, o estímulo à sonegação fiscal e o incremento generalizado da corrupção administrativa. É justamente no sentido de se entender que a eficácia funcional do Estado depende principalmente da honestidade e da eficiência com que atuam os agentes públicos. Eles são considerados um longa manus do Estado, suas atividades possuem reflexos de forma positiva ou negativa na coletividade, principalmente, com relação à formação moral e política dos cidadãos e no respeito que esses devem ter para com os entes públicos. Isso é essencial para a própria solidez do Estado Democrático de Direito, que foi pensado por nossa Constituição Federal.

A corrupção pública atinge a manutenção do Estado Democrático de Direito, sendo que a Administração Pública justamente deveria respeitar os princípios constitucionais que estão estabelecidos na Constituição Federal de 1988, em seu art. 37, que são: legalidade, moralidade, publicidade, impessoalidade e eficiência. 
Argumenta Miranda (2014, http://www.conamp.org.br) que agente público não pode se afastar desses princípios, sob pena de estar comprometendo o adequado funcionamento da administração pública e, consequentemente, causar uma deficiência das prestações sociais de responsabilidade do Estado.

Quando existe uma administração pública corrupta, irá acontecer, como consequência, uma deterioração dos bens públicos. A prioridade passa a ser não a satisfação do interesse geral, mas a de interesses privados de seus gestores corruptos. Conforme Gómes (2016, p. 166-167), a corrupção introduz incentivos considerados perversos na relação entre agentes públicos, particulares e empresas, que, nas suas decisões, sempre vão levar em conta a variável da corrupção.

Quando a corrupção é generalizada, as práticas de suborno e a captação de porcentagens de valores dos contratos são comuns por parte de quem decide adjudicação de contratos públicos. E, da mesma forma, quando bens e serviços são contratados por administração corrupta, geralmente, são de baixa qualidade.

Para Garcia (2013, p. 49), quando a corrupção acontece na esfera estatal, indica o uso ou omissão, de forma inapropriada, pelo agente público, do poder que a lei lhe outorgou. Ele faz o uso inadequado desse poder porque busca uma vantagem indevida, tanto para si como também para terceiros. O desvio de poder e enriquecimento ilícito são elementos característicos da corrupção que ocorre na esfera estatal. Relega para um plano secundário os fins legítimos que foram contemplados nas normas.

Precisamente neste aspecto pode-se analisar os reflexos negativos que a corrupção causa com relação à confiança nas instituições públicas. Lembrando que nas palavras de Moisés (2013a, p.214), a corrupção está presente em todas as esferas da vida pública brasileira, caracterizando um quadro fora de controle, considerado por alguns como uma realidade de natureza endêmica, em relação à qual o sistema político não foi ainda capaz de desenvolver eficazes fórmulas, de forma institucional, para o seu combate.

Conforme expresso no tópico anterior, fundamentado em bibliografia nacional e estrangeira, é fundamental que o cidadão confie nas instituições públicas, como um requisito preponderante para o bom e legítimo funcionamento da democracia. As instituições, por sua vez, devem ser probas e atuar com eficiência e honestidade, respeitando o objetivo para o qual foram criadas. Quando assim fizerem terão a confiança e o apoio dos cidadãos. 
As instituições inspiram confiança quando são coerentes com seus fundamentos legais, como também com a sua legitimidade, conforme Lopes (2013, p. 322-323), quando as instituições sinalizam imparcialidade, universalismo, probidade e justeza na relação com os cidadãos. Por outro lado, as instituições despertam desconfiança quando exprimem o contrário. É justamente nesta afirmação que a corrupção possui um protagonismo enorme. Porque, mais uma vez, conforme defende Cortina (1998, p. 98), a confiança mútua é um produto de primeira necessidade desde o começo da história humana. $^{4}$

A corrupção, como também a desigualdade, nas palavras de You (2005, p. 02), têm um impacto negativo sobre as normas e percepções de confiabilidade. Sociedades com regras processuais justas (democracia), administração correta de regras e distribuição de renda acertada, produzem incentivos para um comportamento confiável, desenvolvem normas de confiabilidade e aumentam a confiança interpessoal. ${ }^{5}$

Quando as instituições são capazes de demonstrar, de modo inequívoco, o universalismo, a imparcialidade, a justeza e a probidade de seus procedimentos, assegurando que os interesses dos cidadãos sejam efetivamente levados em conta pelo sistema político, geram apoio, solidariedade e ganham a confiança dos cidadãos. Ocorrerá o contrário, quando se estiver diante de práticas corruptivas. Essas acarretarão danos na confiança que se deve ter nas instituições, trazendo prejuízos às mesmas, na sua credibilidade, na confiança social e na própria democracia.

Conforme bibliografia sobre a questão da importância da confiança nas instituições públicas e também os efeitos negativos causados pela corrupção, pode-se definir o primado da lei no sentido de as instituições públicas, atenderem, de forma proba, com igualdade, transparência, aos objetivos para os quais foram criadas legalmente.

\footnotetext{
${ }^{4}$ En este orden de cosas, há tenido la corrupción un especial protagonismo como señal de alarma que há recordado algo tan evidente como que la confianza mutua es un producto de primera necesidad desde el comienzo de la historia humana.

${ }^{5}$ I argue that the fairness of a society affects its level of social trust more than does its homogeneity. Societies with fair procedural rules (democracy), fair administration of rules (freedom from corruption), and fair (relatively equal and unskewed) income distribution produce incentives for trustworthy behavior, develop norms of trustworthiness, and enhance interpersonal trust. Based on a multi-level analysis using the World Values Surveys data that cover 80 countries, I find that (1) freedom from corruption, income equality, and mature democracy are positively associated with trust, while ethnic diversity loses significance once these factors are accounted for; (2) corruption and inequality have an adverse impact on norms and perceptions of trustworthiness; (3) the negative effect of inequality on trust is due to the skewness of income rather than its simple heterogeneity; and (4) the negative effect of minority status is greater in more unequal and undemocratic countries, consistent with the fairness explanation.
} 
A corrupção justamente traz a ideia, sempre negativa, de estar ocorrendo uma transgressão, um desrespeito ao que é estabelecido legalmente, para aquilo que a instituição pública foi criada. Desvirtua as determinações legais, pois existe um descumprimento ao que fora estabelecido. Ela traz consequências muito negativas com relação à qualidade da democracia e à confiança nas instituições públicas, que passam a não cumprir o objetivo para o qual foram criadas, qual seja, atender, fundamentalmente, de forma igualitária, o interesse público.

A desconfiança política nas instituições, causadas pelas práticas corruptivas, deve-se, então, ao fracasso das possibilidades de as instituições realizarem as suas atribuições, que estão estabelecidas legalmente. Sobrevem a alienação e a indiferença dos cidadãos, diante da vida política do país. E, principalmente, a descrença de que as instituições públicas, de fato, vão garantir os seus direitos.

A confiança nas instituições públicas precisamente decorre de elas respeitarem o chamado primado da lei, tradução livre da expressão rule of law, da língua Inglesa, usada no presente estudo, que quer refletir sobre o seu significado.

Mignozzetti (2013, p. 264- 268), ao abordar com pertinência este assunto, observa que um dos pressupostos para a boa democracia e a consequente confiança nas instituições públicas é que se respeite o primado da lei, defendendo que ele é um dos principais pilares da sustentação do regime democrático. Pode ser definido basicamente como, a lei valendo igualmente para todos os indivíduos, atingindo a todos sendo que ninguém estaria acima dela. Demonstrando, alguns de seus principais aspectos são: o fato de a lei ser criada para ser aplicada para todos igualmente; a supremacia do estado de direito; a corrupção estar sob controle efetivo; uma burocracia que esteja preparada de acordo com as normas legais estabelecidas; uma força policial que seja eficiente; cidadãos possuírem efetivo acesso às cortes e a justiça ser limpa; a existência de agências de responsabilização horizontal - traduzido livremente do termo accountability, que assegurem o cumprimento da lei pelos diversos órgãos de Estado. Para o autor, o Estado com essas características, como consequência, tem pontos muito positivos com relação à qualidade da democracia.

Seguindo essa linha de argumentação, a corrupção transgride o primado da lei e, atualmente, é definida no sentido de estar ocorrendo a apropriação privada de algum bem público. Assim, por exemplo, caso a prática do suborno seja recorrente, seria diagnosticado que, em primeiro lugar, o primado da lei foi subvertido pelo fato de que esse é um procedimento que nada tem de imparcial e justo. 
Nas palavras de Moisés (2013b, p.48-49), quando nas instituições prevalece a ineficiência ou a indiferença institucional, diante de demandas que asseguram direitos dos cidadãos, garantidos por lei, ou generalizam-se as práticas de corrupção, de fraude ou de desrespeito ao interesse público, cria-se um ambiente de suspeição, desconfiança, de descrédito e de desesperança. Como consequência, floresce, então, a desconfiança e o distanciamento dos cidadãos em relação à política e às instituições democráticas.

Gómes (2016, p. 170) confirma o que aqui é defendido, pois seus estudos demonstram que, nos países onde existe maior incidência de corrupção, ocorre um menor grau de confiança institucional e de confiança recíproca, ou seja, ocorre a destruição de um dos elementos do capital social do país, que é o de confiar nas suas instituições.

\section{EFEITOS NEGATIVOS DA CORRUPÇÃO PÚBLICA NA QUALIDADE DO REGIME DEMOCRÁTICO: EXTREMA DIREITA, CULTURA DO ÓDIO E APATIA POLÍTICA}

O conceito de democracia é considerado de fácil compreensão. Usando os ensinamentos de Rollemberg (2010. p. 16) pode ser definida como um sistema de governo. Para ser democrático deve apresentar eleições regulares, sem fraudes e realmente competitivas, liberdade de imprensa e de organização, alternância no poder, independência dos três poderes e o direito de qualquer cidadão de votar e ser votado.

As práticas corruptivas trazem efeitos danosos à qualidade do regime democrático. Consoante Gómes (2016, p. 164), a corrupção corrói as instituições, substitui o governo das leis pelo decisionismo, aniquila o princípio de serviço e interesse geral dos órgãos públicos. Os comportamentos corruptivos deterioram as estruturas onde ocorrem, da mesma forma que se comunicam com o restante do tecido social e político. E, arremata Quinto (2012, http://www.usp.br) dentre os males causados pela corrupção no Brasil, um dos principais é justamente a ameaça à democracia, principalmente em relação à qualidade do regime.

Nesta terceira parte deste artigo científico serão abordados alguns dos principais efeitos danosos que a corrupção traz com relação ao regime democrático. Dentre muitos e sem a possibilidade de esgotar tal análise, quer-se salientar que além de suscitar muita desconfiança dos cidadãos nas instituições públicas, produzindo efeitos como prejuízo 
na legitimidade e qualidade do regime político, o enfraquecimento da democracia legitima o discurso de extremismos da direita, alimenta culturas racistas e a cultura de ódio.

Em relação ao primeiro ponto, referente ao prejuízo na legitimidade e qualidade do regime político, Gabardo (2011, p.139) lembra que a corrupção pode ser uma verdadeira inimiga à democracia e ao desenvolvimento de uma sociedade, inclusive causando a deturpação dos valores sociais e a falta de legitimidade estatal em seus comandos frente aos seus comandados que ficam incrédulos.

A prática da corrupção acarreta prejuízo na confiança dos cidadãos às suas instituições democráticas. Mignozzetti (2013, p. 268-269) argumenta que a corrupção tem um grande impacto na legitimidade do regime, pois o uso de dinheiro ou de qualquer outro meio que seja público, para algum fim privado, subverte a própria ideia da finalidade de uma instituição pública, que é prestar um serviço pautado pela equidade e justeza em suas ações. Exemplifica-se essa questão da seguinte forma: se alguém pagou suborno a um servidor público, provavelmente não avaliará bem o desempenho do órgão a que o servidor está vinculado, mesmo que tenha ficado satisfeito com a rapidez do serviço após o pagamento desse suborno.

Em interessante pesquisa intitulada: Corrupção e efeitos na memória discursiva, (NUNES, 1999, http://www.sbpcnet.org.br) respondendo ao problema que a norteou investigar quais efeitos-sentido de memória discursiva podem ser identificados na tradição do pensamento político ocidental no que tange à corrupção - chegou a três conclusões muito pertinentes, que serão tratadas nesta terceira parte do texto. Resultados da citada pesquisa indicaram que os efeitos de memória discursiva de aceitação da corrupção afetam tanto a legitimidade do Estado democrático de direito, como também atingem o princípio que estabelece que ninguém está acima da lei na democracia. Primeiro, porque quando acontecem as práticas corruptivas o princípio da igualdade política, que é inerente ao regime, é fraudado. Isso ocorre porque os protagonistas podem manter o poder e benefícios políticos desproporcionais aos que alcançariam se competissem politicamente de forma legítima. Segundo, a dimensão republicana da democracia é distorcida. Neste cenário as políticas públicas resultam de acordos de bastidores que favorecem interesses considerados espúrios. E finalmente, a falta de responsividade gerada pela priorização dos interesses privados em detrimentos dos públicos leva a uma crise de legitimidade democrática que coloca em risco o sistema político. 
Moisés (2013b, p. 38), destaca ainda, que a corrupção também está ligada à questão da legitimidade política. Produz efeitos nefastos na qualidade da democracia, afeta a confiança dos indivíduos e o apoio dos cidadãos ao regime político. É através do julgamento das instituições feito pelos cidadãos, influenciado diretamente por sua cultura política e por sua experiência para com as instituições, que se formam atitudes de apoio, ou, nas palavras de Lopes (2013, p. 313), de reprovação política, com relação a elas.

Baseando-se uma vez mais na bibliografia estrangeira (LAVALLÉ, 2006, http://www.cairn.info/revue-afrique-contemporaine-2006-4-page-163.htm), observa-se que estudos empíricos sobre o assunto confirmam o impacto negativo da corrupção sobre a legitimidade das instituições políticas: ela reduz a confiança nos governos. Nos países corruptos os cidadãos estão menos confiantes em seus sistemas políticos. ${ }^{6}$

Para Moisés (2013a, p. 202-231), os seus efeitos negativos influenciam a legitimidade e a qualidade da democracia, quando comprometem o princípio do regime democrático, em que ninguém está acima da lei. Contribui para o esvaziamento dos mecanismos de responsabilização de governos. A aceitação social da corrupção afeta a qualidade da democracia num sentido primordial. Ela diminui a adesão ao regime e, principalmente, estimula a aceitação de escolhas autoritárias que podem até converterse em alternativas contra o regime em situações de crise. Embora se argumente que essa possibilidade seja cada vez mais difícil de ocorrer nos tempos atuais, o risco que ela oferece está diretamente associado com os efeitos da aceitação da corrupção, somados com a desconfiança dos cidadãos em relação às instituições democráticas. ${ }^{7}$

Podemos destacar que uma das principais consequências da corrupção pública, com relação à democracia é justamente fragilizar o regime, facilitando a escolha de governos autoritários, ou seja, a crise na democracia, poderá trazer excessos de extrema direita. Passam a ser comuns ideias radicais que legitimam regimes antidemocráticos,

\footnotetext{
${ }^{6}$ Les rares études empiriques effectuées à ce sujet confirment l'impact négatif de la corruption sur la légitimité des institutions politiques. Della Porta (2000) montre que la corruption réduit fortement la confiance dans les gouvernements en Italie, en France et en Allemagne. Anderson et Tverdova (2003) établissent qu'en Europe de l'Est et de l'Ouest, les citoyens de pays corrompus sont moins confiants dans leurs systèmes politiques. Des conclusions similaires ont été obtenues pour les pays d'Amérique latine (Seligson, 2002) et d'Asie de l'Est (Chang et Chu, 2006).

${ }^{7} \mathrm{~A}$ evidência de que a corrupção fragiliza o apoio de massa ao regime também foi demonstrada por Seligson em um estudo sobre alguns países latino-americanos, e a sua influência para a escolha de modelos anti-institucionais de democracia, por eleitores latino-americanos e brasileiros, foi apontada por Moisés e Carneiro. Ambas as pesquisas são confirmadas pelos dados apresentados nestes estudos e referem-se a situações que podem deixar em aberto o risco de que alternativas políticas ao regime democrático ganhem apoio de massa, além de mostrar que a corrupção rebaixa a qualidade do regime democrático.
} 
onde se defende que estes são melhores porque não possuem práticas corruptivas. Ou seja, que o totalitarismo não é corrupto, mas baseado na ética e honestidade.

Observa-se que o Brasil passa por um momento neste aspecto. Tendo como pano de fundo que as práticas corruptivas principalmente na administração pública e na política são endêmicas e incontroláveis, percebe-se o crescimento de discurso da extrema direita, com ideias que pregam uma limpeza moral na administração pública, discurso de ódio e ideias racistas. No sentido de se afirmar que a democracia não cumpriu seu papel, que não funcionou e que se precisa, na atual realidade, de um regime mais rigoroso, ditatorial talvez, que efetivamente combata a corrupção, para arrumar o caos, supostamente causado por uma democracia mal administrada.

Em interessante material de pesquisa, intitulado de Crise da Democracia e extremismos de direita (SOLANO, 2018, http://library.fes.de/pdf-files) é feita uma análise que teve como objetivo entender o crescimento das novas direitas brasileiras, principalmente da extrema direita mais antidemocrática. No texto em questão, foram mapeados resultados de entrevistas com simpatizantes de um pré-candidato à Presidência da República do Brasil, nas eleições de 2018. Delinearam-se os principais elementos de identificação dos eleitores com o discurso do pré-candidato, fazendo-se, como consequência, uma análise empírica e teórica das condições do surgimento desse fenômeno, da extrema direita, no Brasil.

Essa mesma pesquisa cita dados publicizados pelo lbope, mostrando que em 2017, a primeira preocupação dos brasileiros foi a corrupção. Foram 62\% de entrevistados que a consideravam o grande problema do país, frente a 9\%, m 2011. A preocupação com a corrupção estava na frente dos problemas históricos como segurança e saúde. Na referida pesquisa lbope, demonstrou-se que os brasileiros enxergam um sistema político totalmente corrompido. Para os entrevistados, o monopólio da luta contra a corrupção em mãos de grupos populistas, punitivos, moralistas e com interesses políticos, deixou como legado um crescente sentimento antipolítico, da mesma forma, a ideia de que política é sinônimo de corrupção e, no dito popular: nenhum político presta. (SOLANO, 2018, http://library.fes.de/pdf-files)

Para os entrevistados, o pré-candidato à presidência da República, eleições de 2018, que possui o discurso de extrema direita, representaria o tipo do político honesto em contraposição à classe política corrupta, (SOLANO, 2018, http://library.fes.de/pdffiles) sendo o único, ou um dos únicos políticos honestos do Brasil. As entrevistas realizadas demonstram que, para os entrevistados, a corrupção perpassa todos os 
partidos. Não haveria diferença entre esquerda e direita, porque o que preocupa os políticos é somente seu próprio benefício e interesse. Observou-se uma absoluta negação da política, não por questões ideológicas ou programáticas, mas porque é vista como uma atividade suja, vergonhosa e corrupta por natureza.

Da mesma forma observa-se, no discurso de movimentos de extrema direita, o discurso de ódio e da intolerância, fomentando discriminação e racismo, através de rejeição de políticas públicas de inclusão social e de quotas, por exemplo. Tais políticas inclusivas que objetivam a integração no sistema de ensino de pessoas que não teriam maiores oportunidades devido a sua condição social, são repugnadas pelas pessoas que repetem esse discurso de ódio.

Mais uma vez cita-se a pesquisa, que demonstra as ideias da extrema direita, na qual os entrevistados se posicionaram negativamente com relação às políticas públicas como Bolsa Família ou cotas raciais universitárias. Para eles, tais políticas inclusivas, fomentam a preguiça, o clientelismo e fazem do cidadão alguém passivo, que fica parasitando no Estado. Da mesma forma, que seriam utilizados por um partido, identificado como sendo da esquerda, de forma eleitoreira, para garantir o voto dos mais pobres e mantê-los sob controle. Foi muito comum entre os entrevistados o argumento de que, por serem sujeitos que pagam seus impostos e, estariam, com isso, sustentando pessoas, a quem os entrevistados se referem, de forma pejorativa: "sustento os vagabundos que não fazem nada. A gente trabalha, para sustentar esses preguiçosos $e$ esses bandidos de Brasília. A gente sustenta todo o mundo". (SOLANO, 2018, ttp://library.fes.de/pdf).

Nesta ideologia de extrema direita, que possui muitos adeptos no Brasil conforme demonstra a referida pesquisa, aqui sucintamente analisada, os cidadãos, economicamente mais desfavorecidos e que são beneficiários de políticas sociais existentes seriam parasitas do Estado. O entendimento é no sentido de que estes não se esforçam o suficiente no trabalho e, por sua vez, o Estado faz uso destas políticas públicas para controlar eleitoralmente tais grupos.

O grande perigo neste tipo de movimento, em que pese a liberdade de expressão, garantida pela Constituição Federal de 1988, é que, tais indivíduos, com ideias extremistas possam ser eleitos e querer instaurar regimes radicais, ou aspectos totalitários na administração pública. Lembrando que muitos dos regimes ditatoriais, que aconteceram na América do Sul e também no Brasil, foram apoiados pela maioria da população e até pela imprensa. 
Pensando a última ditadura que o Brasil viveu, de 1964 até 1985, embora exista vasta bibliografia sobre o período, está focada em dados e relatos relacionados à violência que se praticou no período, pouco se pesquisou e escreveu no sentido de se compreender as relações da sociedade com o regime que iniciou em 31 de março de 1964. Rollemberg (2010. p. 10) observa que os estudos se concentram no sistema e nos instrumentos repressivos, restando a pergunta: como a ditadura se manteve por 21 anos? Já que todos se tornaram resistentes a ela e eram democratas?

Se a resistência e sua memória sempre identificaram as ditaduras à tirania, não raras vezes, estas foram reivindicadas até mesmo como salvadoras da própria democracia, dos valores nacionais e sociais, consideradas como sendo o único caminho, o fio condutor a uma transformação radical da sociedade. Nas palavras de Rollemberg (2010. p. 15) em diferentes circunstâncias, a democracia é que foi rejeitada.

Muitos ditadores foram amados, quando se fala de ditaduras pessoais, não por terem sido temidos, mas provavelmente porque expressavam valores e interesses da sociedade que, em dado momento, eram outros que não os democráticos. Da mesma forma, tivemos experiência autoritárias e ditatoriais no século $X X$, legitimadas pelo apoio de significativas parcelas da sociedade, principalmente pelas camadas populares. Conforme Rollemberg (2010. p. 15) essa compreensão não serve para justificar tais experiências, mas sim, para compreender, perceber o autoritarismo como traço de união entre o passado e o presente, das presenças que acompanham as mudanças.

A experiência brasileira com relação à Ditadura Militar, abordado por Silva (2014, p. 10-11), foi o regime instaurado em $1^{\circ}$ de abril de 1964 que durou até 15 de março de 1985. Aspectos muito interessantes de corrupção aconteceram neste período da história brasileira. Observa Gasparotto (2012, p. 16-18) que a Ditadura Militar possuía caráter autoritário e nacionalista. Teve início com o Golpe Militar que derrubou o governo do então presidente, eleito de forma democrática, João Goulart e terminou quando José Sarney assumiu o cargo de presidente, dando início ao período conhecido como Nova República. Rodeghero (2007, p. 95) lembra que, apesar das promessas iniciais de uma intervenção breve, a Ditadura Militar perdurou por 21 anos. Foram postos em prática, durante este período vários Atos Institucionais, culminando no Al - 5, de 1968, que vigorou até 1978.

O regime militar brasileiro adotou como bandeira uma diretriz nacionalista, tendo como principais propósitos: combater a corrupção e derrotar o comunismo. Destaca Neumann (1985, p. 34) que o regime militar brasileiro inspirou o modelo de outros 
regimes militares e ditaduras por toda a América do Sul, trazendo a sistematização da Doutrina de Segurança Nacional, que justificava as ações militares como forma de proteger o interesse e a segurança nacional em tempos de crise.

A noção de corrupção que era assimilada pelas forças armadas, ressalta Starling (2012, p. 213-215), estava associada à identificação de uma desonestidade específica, que era o mau trato do dinheiro público, ou seja, o de furto. Neste sentido, a corrupção era resultado dos vícios produzidos por uma vida política de baixa qualidade moral e também estava associada, às vésperas do golpe, ao comportamento viciado dos políticos diretamente vinculados ao chamado regime nacional-desenvolvimentista. Pregavam os militares que os políticos desonestos podiam trocar de cargos, mas continuavam os mesmos; a democracia não alcançava destituí-los. A ideia de que a sociedade se regenera, mas a política continua perversa moldou a lógica que orientou 0 regime militar no combate à corrupção. Nessa lógica, o golpe de 1964 justificou parte importante de sua funcionalidade ao produzir uma espécie de intervenção máxima capaz de acabar com os corruptos e garantir aquilo que os militares acreditavam ser a boa ordem punitiva: o julgamento dos civis considerados incapazes de gerir a coisa pública.

Ressalta-se que o golpe militar, teve como um dos principais objetivos, além de combater o comunismo, o de combater à corrupção, no que foi apoiado pela maioria da população brasileira. Este é o perigo de ideias extremistas. Elas encontram muitos adeptos dentre a população, conforme se verifica na realidade brasileira atual. Silva (2014, p. 11-12) observa que, inclusive a imprensa, hoje chamada de mídia, colaborou na preparação da intervenção militar que ocorreu no Brasil há 50 anos, em 31 de março de 1964. Ela cumpriu rigorosamente esse papel na preparação e legitimação do golpe de 1964. Usou todo o seu prestígio para convencer parte da população, especialmente a classe média, a aderir aos propósitos das elites econômicas vinculadas aos interesses do capitalismo internacional. Ironicamente, após a instalação do regime, justamente a imprensa passou a sofrer censura.

A Ditadura Militar brasileira atingiu seu apogeu em 1970 com o chamado milagre brasileiro, conforme demonstra Brum ( 1995, p, 165-225), no mesmo período o regime censurava todos os meios de comunicação, torturava e exilava os seus dissidentes. A partir da década de 1980, como nos outros regimes militares que aconteciam na América Latina, a Ditadura Militar entrou em decadência. O governo não conseguia estimular a economia, nem diminiuir a inflação que era crônica a altíssima. Tal realidade social deu impulso aos movimentos pró-democracia. 
Observa Leal (2013, p , 141) que mesmo no regime de exceção das décadas de 1960 a 1980, após ficar evidente que o perigo do comunismo não era tão grande como se imaginava, foi a corrupção outra base argumentativa de sustentação da ditadura militar. Dito de outra forma por Starling (2012, p. 218) a corrupção fazia parte da essência do regime militar e, em qualquer circunstância, representa uma ameaça à sobrevivência das sociedades democráticas - não apenas porque conduzia à perda de referenciais que levam os homens a agir em prol do interesse público, mas principalmente porque ela desata o processo da vida política e destrói a coisa pública.

Mais uma vez, destaca Leal (2013, p, 87-88) que com o fim da Ditadura Militar e o retorno dos civis ao governo, cresceram significativamente, os casos de corrupção que vêm a público, como foi a Caso Capemi, também chamado escândalo da Mandioca (1979 e 1981); Caso Coroa-Brastel (1985), escândalo do Ministério das Comunicações, que envolveu um grande número de concessões de rádios e TVs para políticos aliados, concedidas em troca de cargos, votos ou apoio ao então presidente José Sarney.

A corrupção não era um problema para a ditadura. Ao contrário, como ensina Starling (2012, p. 219) ela alimentou o comportamento desviante do regime militar, degradando a lei e esvaziando o corpo político de seu significado público.

A análise destes dados históricos referentes à corrupção que também ocorria, e muito, durante a Ditadura Militar, desmistifica, o dito popular, repetido por muitos, da extrema direita de que, durante as décadas de 1960 até 1980 o Brasil não tinha corrupção, ou, se ela ocorria, era muito pouco diante das denúncias de corrupção que emergem, quase que diariamente. Rebatendo, de forma racional e com base em dados históricos: não há fundamento nos chamados desejos e argumentos populares que pregam que seria muito bom para o país a volta de referido regime.

Garcia (2013, p. 51.) traz que essa observação é necessária na medida em que a maior participação popular, inclusive com o aumento ao acesso aos meios de comunicação, pode conduzir à equivocada conclusão de que, apesar de termos democracia em nosso país, a corrupção teria aumentado. A corrupção, em verdade, sempre existiu. Destaca ele que, em regimes autoritários, no entanto, poucos se atreviam a retirar o véu que a encobria, mostrando-Ihe a face. Os motivos, aliás, são muito conhecidos. Assim, é preciso não confundir inexistência de corrupção com desconhecimento dela. Em ambientes democráticos tem-se "um processo de desocultação da corrupção". 
Reforça Bignotto (2011, p.19) que o argumento que regimes ditatoriais, apoiados pela população, vão combater a corrupção ou que nestes ela não existe, é um argumento falacioso no sentido de que um país que é submetido a uma ditadura, ou onde não existe a liberdade de imprensa, pode parecer como sendo menos corrupto em pesquisas de opinião pelo simples fato de que faltam a ele as características essenciais para a constituição de uma verdadeira esfera pública.

O autoritarismo, ou a volta de uma ditadura militar, desejados por muitos, ovacionados atualmente, principalmente nos discursos de extrema direita, ficam sem argumento diante desta parte histórica apontada no presente artigo científico. Mas é preocupante que regimes extremistas, com base na bandeira política de se combater a corrupção, apoiados até pela imprensa, que após o golpe militar no Brasil, foi a primeira a ser censurada, foram apoiados por vários segmentos da sociedade brasileira.

Destaca Rollemberg (2010. p. 23) que o autoritarismo foi desejado e alguns ditadores foram e ainda são considerados queridos e percebidos como salvadores da pátria por pessoas ou segmentos da sociedade de todas as idades e origens sociais. $\mathrm{O}$ autoritarismo constituíu elemento da cultura política de muitas sociedades. Observa-se que, antes de atribuir a existência de regimes ditatoriais na América do Sul, e no Brasil, somente à influência dos Estados Unidos, as ditaduras latino-americanas dos anos 1960 e 1970 tinham, desde as articulações do golpe e durante o regime, apoio de setores da sociedade para o golpe. O Brasil, em 1964, e o Uruguai de 1973, o Chile, em 1973 e a Argentina, em 1976 passaram a ter governos ditatoriais. Os governos legítimos e legais foram depostos e acusados de incapacidade e irresponsabilidade. Os novos governos, representados por militares, mas não exclusivamente formados por eles, seriam a representação da salvação, enquanto o que havia antes nos países, era o caos. Neste discurso, a esquerda ia entregar o país a Moscou, adotando-se sempre o discurso do anticomunismo e da salvação da nação.

Não se quer negar as resistências, nem muito menos se está dizendo que a história está fadada às ditaduras. Mais uma vez nas palavras de Rollemberg (2010. p. 26) está-se simplesmente lidando com uma constatação: um século marcado por muitas ditaduras, em diferentes países e continentes, com culturas, tradições e passados diversos, que tiveram apoio da sociedade. Eis aí uma preocupação. $O$ apoio popular que discursos totalitários já tiveram historicamente, e que atualmente se assiste no Brasil, no surgimento de discurso de extrema-direita. 
A fragilidade do sistema democrático também fomenta o surgimento de preconceito, racismo e discriminação, que, aliada à falta da busca pela verdade conduzem a um ambiente propício para o desenvolvimento do chamado Discurso do Ódio. Conforme Carcará (2017, http://www.unifafibe.com.br) essa situação impede o acesso das minorias, favorece o surgimento de estereótipos e propicia que os preconceitos se enraízem cada vez mais no seio da sociedade.

O racismo pode ser definido como sendo uma doutrina segundo a qual todas as manifestações culturais, históricas e sociais do homem e os seus valores dependem da raça e que existiria uma raça superior (ariana ou nórdica) que se destina a dirigir o gênero humano. Observa Assis (2011, p. 35- 38) que as concepções racistas constituem um fenômeno antigo, cujas teorias estão a serviço da violência, da opressão, da ignorância e da destruição. Ressalta-se que a biologia e a genética afirmam que as diferenças na formação anatômica-fisiológica dos seres humanos não produzem raças. Raça, portanto, é uma palavra criada para avaliar, julgar e manipular diferenças biológicas e genéticas. Em estudo antropológico, as teorias racistas não são científicas, mas seriam falsas e irracionais. Implicam práticas culturais, econômicas, sociais e políticas usadas para justificar a violência contra os seres humanos. Geneticistas contestam a existência de raças e confirmam que é impossível estabelecer a superioridade intelectual de um grupo étnico sobre outros. Antropólogos entendem que diferenças entre nações se devem à cultura e não existe alguma que seja superior ou inferior. E, ainda, segundo antropólogos, cultura não é herdada biologicamente, mas é assimilada, sendo adquirida e até mesmo emprestada.

Complementando esta abordagem, em relação ao discurso do ódio, com base em considerações racistas, interessante analisar os dados da pesquisa já citada (SOLANO, 2018, <http://library.fes.de/) no que se refere ao movimento de extremadireita que é escancarado pelos eleitores do pré-candidato a eleições de 2018, que justamente alimenta este discurso racista e de ódio. Observa-se que, ao mesmo tempo em que os entrevistados reconhecem que o Brasil é um país racista, não defendem, entretanto, cotas raciais. Isso acontece porque para eles, estas são racistas e intensificam o racismo pelos dois lados porque os estudantes, brancos, com razão, se sentiriam injustiçados.

As cotas raciais estariam colocando os estudantes brancos numa posição de inferioridade e, segundo alguns entrevistados, menosprezando a capacidade dos negros para entrarem na universidade que querem, sem ajuda do Estado. Elas são, portanto, 
um mecanismo que gera mais racismo, coloca o negro na posição de vítima e o branco na posição de injustiçado. Uma entrevistada de 16 anos argumentou: "Por que negro tem de ter privilégio? Só porque ele é negro? Ele tem as mesmas oportunidades. É só ele se esforçar e estudar, se ele realmente quiser passar na universidade" (SOLANO, 2018, <http://library.fes.de/)

Alerta Assis (2011, p. 243) para os perigos deste tipo de doutrina, intitulada como sendo de ódio, diante da fragilidade das instituições democráticas, observa-se que os políticos de direita, e que muitas vezes alimentam tendências nazistas ou fascistas, têm utilizado este tema para expressar um nacionalismo exacerbado que, em algumas ocasiões, aparece como a mais pura expressão de uma doutrina racista.

Menciona-se esta pesquisa como forma de demonstrar os aspectos de surgimento de radicalismos, extrema direita, que justamente surgem quando existe a desconfiança nas instituições, causada pela corrupção. As práticas corruptivas enfraquecem a confiança no regime, colocam-no em dúvida de ser o melhor, atingem e prejudicam a sua legitimidade e acabam legitimando discursos extremistas. Este extremismo da direita que promete acabar com a corrupção, e que, de forma preocupante, é apoiado pela população, faz surgir figuras mitológicas e heróis populares, que prometem, de forma radical, moralizar o Estado e a sociedade, através de sistemas totalitários, alimentando o discurso de ódio. Pregam que as pessoas carentes que precisam de políticas inclusivas, estão parasitando no Estado, devem trabalhar, ou concorrer em igualdade de condições com todos os demais.

É muito pertinente observar que, no Brasil há 25 anos, a maior preocupação referia-se à transição para a democracia. Posteriormente, houve o período de discussão e de consolidação do regime, sendo, nos dias de hoje, a preocupação maior, a qualidade da democracia no Brasil. Conforme Quinto (2012, http://www.usp.br), o país já sente os efeitos danosos da corrupção em sua democracia, em especial quando se observa a queda de qualidade na pouca participação e decrescente interesse da população por política de um modo geral.

A maioria dos brasileiros percebe o aumento da corrupção no transcorrer do tempo. Para Meneguello (2011, p. 70), os brasileiros, em maior parte, identificam-na como tema da agenda pública, consideram um assunto muito sério e manifestam grande juízo negativo sobre as formas de corrupção política, que estão associadas à administração pública. A corrupção, atinge o primado da lei, no sentido de fazer com que a instituição pública não cumpra o objetivo para o qual foi criada legalmente, e, nas 
palavras de Mignozzetti, (2013, p. 270), provoca efeitos negativos na qualidade da democracia, produzindo um aumento da apatia dos indivíduos com relação ao regime, influenciando, inclusive, na qualidade da cidadania.

Observam Gorczevski, Martin (2011, p. 86) que a corrupção conduz à indiferença ou à perda de interesse em participar nos assuntos públicos, aspecto muito negativo, pois a vida do indivíduo também se vicia, gerando apatia social diante dos assuntos públicos.

Nas palavras de Lopes (2011, p. 80), existe uma relação muito grande entre os altos índices de corrupção e o desenvolvimento democrático. Altos níveis de corrupção estão associados a fracos níveis de desenvolvimento social, econômico e político. A corrupção que ocorre na esfera pública traz como consequência a diminuição na qualidade de vida da população, e seus efeitos nocivos variam de acordo com as peculiaridades de cada país.

Miranda (2014, http://www.conamp.org.br) lembra que são inegáveis as consequências prejudiciais que a corrupção traz para a tutela dos direitos fundamentais da pessoa humana e para a manutenção do próprio Estado Democrático de Direito. Ela configura um dos fatores da crise da governabilidade, colocando em risco a democracia, na medida em que gera desconfiança nas instituições estatais, conforme já se abordou na primeira parte do presente texto.

A conduta irregular de líderes e de partidos políticos compromete a percepção das pessoas sobre as vantagens da democracia em comparação às suas alternativas. Essas práticas corruptivas, e que ficam impunes, fazem as pessoas crerem que tal conduta é parte da rotina usual, tanto do regime democrático como do autoritário. Desqualifica os mecanismos adotados pela democracia para controlar o abuso de poder e para garantir a soberania dos cidadãos com os Estados Democráticos. Compromete também a cooperação social e acaba afetando negativamente a capacidade de coordenação dos governos para atender às preferências dos eleitores.

Nesta parte, destaca-se que os efeitos da corrupção com relação ao regime democrático trazem dentre as suas consequências nefastas o argumento a favor de discursos, que se assiste no Brasil, da extrema direita, que prega até a adoção de regimes totalitários, o discurso do ódio, com a crença e propagação de ideias racistas, como também provoca a apatia social, onde as pessoas passam a não ter o mínimo interesse em participar da vida política, o que também diminuiu, e muito, a qualidade do regime democrático. 
Com relação ao impacto da corrupção e as bases da adesão democrática, procurando a resposta de como diminuir a distância entre a percepção, o juízo moral e a prática política, para Meneguello (2011, p. 78), ideia aqui defendida, aprimorar as instituições, de forma que elas adquiram ou readquiram confiança quanto a seus efeitos, é considerado um dos caminhos fundamentais.

\section{CONSIDERAÇÕES FINAIS}

O presente artigo científico teve como propósito responder à seguinte pergunta, que é o seu problema norteador: quais as consequências da corrupção nas instituições públicas e no regime democrático?

Para se alcançar uma resposta, foram analisados três objetivos, sendo um em cada tópico desta pesquisa. O primeiro objetivo específico, alcançado na primeira parte desse estudo, quis demonstrar a importância de as pessoas confiarem nas instituições públicas. As instituições, que são criadas para atender o interesse público, devem espelhar o chamado primado da lei, o que significa que deverão atender e realizar o que é determinada para elas legalmente, agindo com transparência e probidade.

$\mathrm{Na}$ segunda parte deste texto alcançou-se o objetivo de analisar a ocorrência da corrupção na esfera pública e justamente as consequências que ela gera na confiança que a sociedade deverá ter nestas instituições.

Observa-se que as instituições públicas, precisamente, foram criadas para atender, conforme estabelecido legalmente, aos anseios da população, visando realizar o interesse público. Essas instituições são a consequência da delegação voluntária de soberania e de poder que os cidadãos creditaram aos representantes que elegeram. $\mathrm{Na}$ atualidade um dos maiores desafios é garantir que a administração seja proba. A corrupção justamente compromete isso, gerando desvios de função e desconfiança das pessoas para com elas. Ela prejudica a eficiência e a prestação das atribuições das instituições públicas, de forma proba, prejudicando, assim, o funcionamento do regime democrático

A confiança nas regras de funcionamento de instituições públicas depende, principalmente, de ter ocorrido a realização, na prática, de valores como universalismo, reciprocidade e participação. Se isso não ocorrer, os cidadãos tendem a perceber a política como uma fraude ou como algo em que a diversidade de interesses não está garantida. Da mesma forma, gera desconfiança política quando o cidadão percebe a 
política como uma situação em que os eventuais infratores das regras não sofrem nenhum tipo de restrições ou punições, por parte do sistema político.

$\mathrm{Na}$ terceira parte, finalizando este trabalho e respondendo ao problema que norteou a pesquisa, evidenciou-se alguns dos efeitos negativos que a corrupção gera na qualidade do regime democrático. Considerou-se esta análise como a mais grave, dentro dos efeitos que a corrupção produz, trazendo desconfiança nas instituições públicas e colocando em perigo o regime democrático. Assistiu-se, no país, como uma das consequências principais desta desconfiança, o crescimento de ideias de extrema direita, bem como o surgimento de mitos e salvadores da pátria, que resolveriam os problemas decorrentes da corrupção, ou seja, fariam, milagrosamente, o que a democracia não conseguiu fazer.

Movimentos de extrema direita, foram analisados nesta pesquisa sem a pretensão de esgotar o assunto, que se considera extremante complexo. Apontou-se algumas de suas características e principais ideias, que, pregam de forma falaciosa que, para combater a corrupção, aniquilando-a nos quadros e na administração pública, seria uma boa solução a volta de regimes ditatoriais, autoritários.

Com tais afirmações, foi aqui salientado que quando aconteceram regimes ditatoriais, não ocorriam práticas corruptivas, ou se por acaso houvesse, eram muito bem punidas. Demonstrou-se, através de vasta bibliografia, que este argumento não é verdadeiro, mas falso, pois a ditadura militar brasileira, que iniciou em 1964 e terminou em 1985 conviveu, e muito, com a corrupção. O que sucedeu, é que não havia publicidade da corrupção, o que é bem diferente de se afirmar que ela não existia. Mas, uma vez voltando o país ao regime democrático, com o fim da Ditadura Militar e o retorno dos civis ao governo, aumentou, e muito, o número de casos divulgados de corrupção por haver, então, liberdade de imprensa que, durante o regime militar estava censurada.

O que é preocupante, e foi demonstrado no presente estudo, é que historicamente, regimes ditatoriais, foram apoiados pela população. Inclusive no Brasil, a Ditadura Militar que iniciou em 1964, foi apoiada até pela imprensa, apesar de, ironicamente, uma vez instaurado o regime totalitário, ser a imprensa a primeira a ser censurada. Essa realidade de apoio e repetição de ideias extremistas, culto ao salvador da pátria, ou crença de que nos regimes ditatoriais não existe corrupção ocorre por desconhecimento da história, principalmente pela descrença no regime democrático. Passa a população a acreditar em mitos e salvadores da pátria, que irão, uma vez no 
poder, com regimes ditatoriais, com regras duras, sem assistencialismo, arrumar o caos causado pela democracia, que garante participação e direitos.

A percepção social da corrupção afeta a qualidade da democracia num sentido primordial. Ela diminui a adesão ao regime e, principalmente, estimula a aceitação de escolhas autoritárias que podem até converter-se em alternativas contra o governo em situações de crise. Embora se argumente que essa possibilidade seja cada vez mais difícil de ocorrer nos tempos atuais, o risco que ela oferece está diretamente associado aos efeitos da percepção e até de aceitação da corrupção, somado com a desconfiança dos cidadãos em relação às instituições democráticas.

Efeito nefasto da corrupção nas instituições é instaurar a desconfiança e trazer como consequência concepções extremistas, que são baseadas em ideias de ódio, extremos, onde não existe espaço para a democracia. Mostrou-se ainda, que o enfraquecimento da democracia favorece base para discurso de ódio, exaltação de ideias racistas, superioridade étnica e de uns sobre outros, resgatando ideias há muito superadas e combatidas, inclusive pela antropologia.

E finalmente tratou-se sobre o efeito que a corrupção gera debilitando a confiança nas instituições e como consequência, causando o enfraquecimento da democracia, além de provocar a apatia social, pois percebe-se cada vez menos uma participação saudável em assuntos políticos e democráticos. Por isso, a necessidade de se combater a corrupção, aprimorando as instituições, de forma que elas adquiram ou reconquistem a confiança da população, é defendida por esta pesquisadora como um dos caminhos fundamentais.

\section{REFERÊNCIAS}

ASSIS, Olney Queiroz. KUMPEL, Vitor Frederico. Manual de antropologia jurídica. São Paulo, Saraiva, 2011.

BIGNOTTO, Newton. Corrupção e opinião pública. In: AVRITZER, L.; FILGUERAS, F. (Org.). Corrupção e sistema político no Brasil. Rio de Janeiro: Civilização Brasileira, 2011.

BOBBIO, N.; MATTEUCI, N.; PASQUINO, G. Dicionário de política. 5. ed. Brasília: Editora Universidade de Brasília: São Paulo: Imprensa Oficial do Estado de São Paulo, 2000. 
BRUM, Argemiro J. O desenvolvimento Econômico Brasileiro. 14. ed. Petrópolis, RJ, Vozes, 1995.

CARCARÁ, Thiago Anastácio. Discurso do ódio e democracia: participação das minorias na busca pela tolerância. Revista Direitos Sociais e políticas públicas.(UNIFAFIBE) Vol. 05, n. 1, 2017. Disponível em: < http://www.unifafibe.com.br/revista/index.php/direitos-sociais-politicaspub/article/view/218/pdf_1>. Acesso em: 24 ago. 2018.

CORTINA, Adela. Hasta um pueblo de demônios: ética pública y sociedade. Madrid, España: Santillana Ediciones: Taurus, 1998.

CUNHA, Ary Ferreira da. Causas e consequências da corrupção: uma breve introdução jurídico-económica. In: CUNHA, Ary Ferreira (Coord.). IV Congresso de Direito Fiscal. Porto, Portugal. ISBN - 978-972-788-985-3; out.2014.

GABARDO, E.; REIS, L. E. O gerencialismo entre eficiência e corrupção: breves reflexões sobre os percalços do desenvolvimento. In: SILVEIRA, R. D. da; CASTRO, R. A. P. de. (Org.). Estudos dirigidos de gestão pública na América Latina. Belo Horizonte: Fórum, 2011.

GARCIA, E.; ALVES, R. P. Improbidade administrativa. 7. ed., rev., ampl. e atual. São Paulo: Saraiva, 2013.

GASPAROTTO, Alessandra. 0 terror renegado: a retratação pública de integrantes de organizações de resistência à ditadura militar no Brasil (1970-1975). Rio de Janeiro: Arquivo Nacional, 2012.

GÓMES, Santiago Roura. Alguns aspectos-chave do combate à corrupção na Administração Pública. In: MENDES, G.F.; BRANCO, P.G.G. V Seminário Internacional de Direito Administrativo e Administração Púbica - Tendências da Administração Pública- Escola de Administração de Brasília - IDP. Série IDP Eventos. Brasília, 2016.

GORCZEVSKI, C.; MARTIN, N. B. A necessária revisão do conceito de cidadania: movimentos sociais e novos protagonistas na esfera pública democrática. Santa Cruz do Sul: EDUNISC, 2011. Disponível em: <http://www.aedmoodle.ufpa .br /pluginfile. php?file=\%2F199230\%2 Fmod_resource \%2Fcontent\%2F1\%2F protagonismo\%20e\%20movimento\%20sociais.pdf>. Acesso em: 13 dez. 2016.

LAVALLÉ, Emmanuelle. Corruption et confiance dans les institutions politiques : test des théories fonctionnalistes dans les démocraties africaines. Afrique contemporaine 2006/4 ( $n^{\circ} 220$ ). 278 pages. Disponível em : <http:/ /www.cairn.info/ revueafrique-contemporaine-2006-4-page-163.htm>. Acesso em: 16 ago. 2016.

LEAL, Rogério Gesta. Patologias corruptivas nas relações ente Estado, administração pública e sociedade: causas, consequências e tratamentos. Santa Cruz do Sul: EDUNISC, 2013.

LIVIANU, Roberto. Corrupção: incluindo a Lei Anticorrupção. 2. ed. São Paulo: Quartier Latin, 2014. 
LOPES, Cleber da Silva. Por que os brasileiros desconfiam da polícia? Uma análise das causas da desconfiança na instituição policial. In: MOISÉS, J. A.; MENEGUELLO, R. (Org.). A desconfiança política e os seus impactos na qualidade da democracia. São Paulo: Editora da Universidade de São Paulo, 2013.

LOPES, José Mouraz. O espectro da corrupção. Coimbra, Portugal: Almedina, 2011.

MENEGUELLO, R.; MOISÉS, J. Á. O papel da confiança para democracia e suas perspectivas. In: MOISÉS, J. Á.; MENEGUELLO, R. (Org.). A desconfiança política e os seus impactos na qualidade da democracia. São Paulo: Editora da Unniversidade de São Paulo, 2013.

MENEGUELLO, Rachel. O lugar da corrupção no mapa de referências dos brasileiros: os aspectos da relação entre corrupção e democracia. In: AVRITZER, L.; FILGUERAS, F. (Org.). Corrupção e sistema político no Brasil. Rio de Janeiro: Civilização Brasileira, 2011.

MIGNOZZETTI, Umberto Guarnier. Impacto da corrupção sobre a qualidade do governo democrático. In: MOISÉS, J. Á.; MENEGUELLO, R. (Org.). A desconfiança política e os seus impactos na qualidade da democracia. São Paulo: Editora da Universidade de São Paulo, 2013.

MIRANDA, Gustavo Senna. Corrupção pública: uma pandemia nacional. 2014. Disponível em: <http://www.conamp.org.br/pt/biblioteca/artigos/item/521-corrupcaopublica-uma-pandemia-nacional.html>. Acesso em: 04 mar. 2016.

MOISÉS, José Álvaro. Cidadania, confiança política e instituições democráticas. In: MOISÉS, J. Á.; MENEGUELLO, R. (Org.). A desconfiança política e os seus impactos na qualidade da democracia. São Paulo: Editora da Universidade de São Paulo, 2013b.

MOISÉS, José Álvaro. Corrupção política e democracia no Brasil Contemporâneo. In: MOISÉS, J. Á.; MENEGUELLO, R. (Org.). A desconfiança política e os seus impactos na qualidade da democracia. São Paulo: Editora da Universidade de São Paulo, 2013a.

MONTESQUIEU, Charles. Do espírito das Leis. São Paulo: Martin Claret, 2002.

NEUMANN, L.; DALPIAZ.O.; Realidade Brasileira: Visão Humanizadora. Petrópolis, RJ: Vozes, 1985.

NUNES, V. F. et al. Corrupção e efeitos na memória discursiva. 1999. Disponível em:<http://www.sbpcnet.org.br/livro/68ra/resumos/resumos/5353_1b052f3519726f8627 1e06c820cfab565.pdf>. Acesso em: 24 ago. 2018.

PRADO, Luiz Regis. Curso de Direito Penal Brasileiro: arts. 289 a 359-H. 3. ed., São Paulo: Revista dos Tribunais, 2004.

QUINTO, Antonio Carlos . Corrupção prejudica a qualidade da democracia brasileira. Agência USP de notícias. Publicado em 15 fev. 2012. Disponível em: http://www.usp.br/agen/?p=88345. Acesso: 24. mar. 2017. 
RODEGHERO, Carla Simone. Regime Militar e oposição. In: GOLIN, T.; BOEIRA, N.; GERTZ, R.; (Org.) República: da revolução de 1930 à Ditadura Militar (1930-1985). V. 4. Coleção História Geral do Rio Grande do Sul. Passo Fundo: Méritos, 2007.

ROLLEMBERG, Denise, QUADRAT, Samantha (organizadoras). A construção social dos regimes autoritários: Legitimidade, consenso e consentimento no século XX. Rio de Janeiro: Civilização Brasileira, 2010.

ROTHSTEIN, Bo. Social Traps and The Problem of Trust: Theories of Institucional design. Cambridge: Cambridge University Press. 2005.

SILVA, Juremir Machado da. 1964. Golpe midiático-civil-militar. Porto Alegre: Sulina, 2014.

SOLANO, Esther. Crise da Democracia e extremismos de direita. ANÁLISE, № 42, maio de 2018. Disponível em:< http://library.fes.de/pdf-files/bueros/brasilien/14508.pdf> Acesso em: 24 ago. 2018.

STARLING, Heloisa Maria Murgel. Ditadura Militar. In: AVRITZER, I.; BIGNOTTO, N.; GUIMARÃES, J.; STARLING, H.M.M.; (Org.) Corrupção: ensaios e críticas. Belo Horizonte: Editora UFMG, 2012.

YOU, Jong-Sung. Corruption and Inequality as Correlates of Social Trust:

Fairness Matters More Than Similarity. The Hauser Center for Nonprofit

Organizations and The John F. Kennedy School of Government Harvard University. November 2005. Working Paper No. 29, p. 02. Disponível em:

<http://cpl.hks.harvard.edu/files/cpl /files/workingpaper_29.pdf>. Acesso em: 22 mar. 2017. 